\title{
Wernicke's encephalopathy following 'hunger strike'
}

\author{
BRIAN PENTLAND \\ B.Sc., M.B., Ch.B., M.R.C.P. \\ CLIFFORD MAWDSLEY \\ M.D., F.R.C.P. \\ University Department of Medical Neurology, Royal Infirmary, Lauriston Place, Edinburgh
}

\begin{abstract}
Summary
A 41-year-old doctor who voluntarily starved himself and developed Wernicke's encephalopathy after intravenus rehydration is described. The need to be aware of this complication of dextrose infusion in the undernourished non-alcoholic patient is emphasized.
\end{abstract}

\section{Introduction}

Wernicke's encephalopathy may present with an acute, sub-acute or chronic onset and it has been emphasized recently that one must not expect the characteristic features of impaired consciousness, ophthalmoplegia and ataxia before making the diagnosis and commencing therapy (Leading Article, 1979). Although classically associated with chronic alcoholism in Western countries, a number of other predisposing conditions exist such as gastrointestinal disorders, hyperemesis gravidarum, thyrotoxicosis, renal dialysis and malnourishment of prisoners of war (Victor, Adams and Collins, 1971; Editorial, 1979).

We describe a patient who was not an alcoholic, who starved himself as a result of a paranoid psychosis and developed Wernicke's encephalopathy when rehydrated.

\section{Case report}

A 41-year-old Indian doctor was found conscious, but uncommunicative and in a poor general state, by his landlord on June 29th 1981, and was admitted late that night to an acute medical ward. He had no family or friends in this country and his landlord's acquaintance with him consisted of a monthly visit to collect the rent. The month before admission the patient had forwarded his rent and had not been seen. The landlord noted that the patient looked thinner than when he had last seen him 2 months before, that his rooms were untidy and his luggage consisted of twenty-nine suitcases of medical texts. The patient was unco-operative at examination and his only communications were 'I am on hunger strike' and 'I must have my certificates from the Royal Colleges of Surgeons'. No amount of persuasion would get him to expand on this. He was clinically dehydrated, unshaven and dirty. He was weak and bed-bound. There was no nystagmus, nor defect of ocular movement. His fundi were normal and there were no focal neurological signs. His urea was slightly elevated at $12.0 \mathrm{mmol} /$ litre and potassium low at $2.6 \mathrm{mmol} /$ litre. Liver function tests, serum proteins and full blood count were within normal limits. Rehydration was started with intravenous saline and 5\% dextrose with potassium supplements.

The following day he was seen by a psychiatrist and was transferred to a psychiatric hospital. By the next day there was no change in his mental state but he was noted to have nystagmus and retinal haemorrhages and was referred for a neurological opinion. When seen later that day he was drowsy and cooperated poorly. He had marked vertical and horizontal nystagmus, conjugate eye movements were defective and there was a flame shaped retinal haemorrhage in each eye. Over the $36 \mathrm{hr}$ from admission to neurological review he had received 2.5 litres of 5\% dextrose and 2 litres of physiological saline.

Treatment with high dose intravenous thiamine was started and within the hour he was persuaded to eat which he then did voraciously. Over the ensuing week, although he remained drowsy for a few days, he became more co-operative and communicative. $\mathrm{He}$ confabulated, claiming to know a number of senior doctors who were visiting the ward for the first time and who had never seen him before. He also partially expanded on his recent history, giving some details of his previous employment which proved to be correct. His claim to have qualified F.R.C.S. was confirmed by the appropriate College and his complaint was that he had not been given honorary status by the other two Colleges of Surgeons. After a week of treatment his general state was much improved although his ocular signs showed little improvement. He became aggressive, refusing again to eat or wash and expressing paranoid ideas and so was transferred 
back to the psychiatric ward for further treatment of his psychotic disorder.

\section{Discussion}

Wernicke's encephalopathy is widely recognised as a nutritional deficiency usually associated with chronic alcoholism (Harper, 1979). It has been described in malnourished prisoners of war (de Wardener and Lennox, 1947; Cruickshank, 1950) and as a complication of therapeutic starvation for obesity (Drenick, Joven and Swendseid, 1967). A 56year-old Danish criminal who went on hunger strike for 2 months was tube-fed for a short period and then returned to hunger strike for a further two months. During this period he drank tea with sugar and developed Wernicke's encephalopathy (Frantzen, 1966). It is well recognized in chronic alcoholic patients that a glucose load in the form of intravenous hydration with dextrose may be the final insult to the exhausted thiamine stores (Wallis, Willoughby and Baker, 1978). An 83-year-old woman who had been unwell for one month developed Wernicke's encephalopathy after admission to hospital and it was suggested that the dextrose-saline given for rehydration may have contributed (Clinicopathological Conference, 1979).

Our patient presented without a clear history of previous ill-health and was uncommunicative. He was clinically dehydrated and rehydration with dextrose-saline precipitated Wernicke's encephalo-气̊ pathy. Patients can respond dramatically to thiamine $\frac{\pi}{2}$ therapy but recovery depends on how soon the $\propto$ thiamine is given and is often incomplete. We suggest $c$ that in any confused patient in whom the cause of $\overrightarrow{\vec{F}}$ dehydration is not obvious thiamine be given prophylactically before rehydration is commenced.

\section{References}

Clinico-pathological Conference (1979) Two geriatric cases. British Medical Journal, 1, 1768.

CruicKSHANK, E.K. (1950) Wernicke's encephalopathy. Quarterly $\vec{\circ}$ Journal of Medicine, 19, 327.

DE WARDENER, H.E. \& LENNOX, B. (1947) Cerebral beriberi $\vec{\omega}$ (Wernicke's encephalopathy). Lancet, i, 11.

DRENICK, E.J., JOVEN, C.B. \& SWENDSEID, M.D. (1967) Occurrence of acute Wernicke's encephalopathy during prolonged starvation for the treatment of obesity. New England Journal of Medicine, 274, 937.

EDITORIAL (1979) Wernicke's preventable encephalopathy. Lancet, i, 1122.

FRANTZEN, E. (1966) Wernicke's encephalopathy. 3 cases occurring $\cdot$ in connection with severe malnutrition. Acta neurologica scandi- $\mathrm{N}$ navica, 42, 426.

HARPER, C. (1979) Wernicke's encephalopathy: a more common음 disease than realised. Journal of Neurology, Neurosurgery and Psychiatry, 42, 226. LEADING ARTICLE (1979) Wernicke's encephalopathy. British Medi-
cal Journal, 2, 291.

VICTOR, M., ADAMS, R.D. \& Collins, G.H. (1971) The Wernicke- $\overrightarrow{0}$ Korsakoff Syndrome, p. 13. Blackwell Scientific Publicatioos, Oxford.

Wallis, W.E., Willoughby, E. \& BakeR, P. (1978) Coma in Wernicke-Korsakoff syndrome. Lancet, ii, 400. 